\title{
Aktivitas Antioxidant, Polifenol Dan Evaluasi Sensori Cokelat Oles Fortifikasi Red Palm Olein Dari Biji Kakao Pilihan KIon Sulawesi Barat
}

\section{Antioxidant Activity, Polyphenols, And Sensory Evaluation Chocolate Spread Fortified Red Palm Olein From Selected Cocoa Beans Clone West Sulawesi}

\author{
${ }^{1}$ Nur Fitriani Usdyana Attahmid, ${ }^{1}$ Dewan Saputra, ${ }^{2}$ Muhammad Yusuf \\ ${ }^{1}$ Program Studi Agroindustri, Politeknik Pertanian Negeri Pangkep, Jl. Poros Makassar - Parepare \\ KM. 83 Mandalle, 90655, Kabupaten Pangkep, Indonesia \\ ${ }^{2}$ Program Studi Teknologi Kimia Industri, Politeknik Negeri Ujung Pandang, Jl. Perintis Kemerdekaan \\ KM. 10 Tamalanrea, 90245, Makassar, Indonesia \\ *Corresponding author: nurfitriani.poltekpangkep@gmail.com
}

Diterima tanggal 08 Mei 2020, Disetujui tanggal 30 Mei 2020

\begin{abstract}
Abstrak
Sulawesi Barat merupakan salah satu penghasil kakao utama dengan kontribusi sekitar $22 \%$ terhadap produksi kakao di wilayah Sulawesi. Pengembangan kakao fermentasi dan tanpa fermentasi dalam pembuatan produk cokelat oles memberikan alternatif baru sebagai pangan fungsional. Penelitian ini bertujuan untuk karakterisasi aktivitas antioksidan, polifenol, karotenoid dan sensori pada produk cokelat oles menggunakan biji kakao pilihan melalui variasi cocoa liquor, gula aren dan red palm olein sehingga diperoleh produk cokelat oles fungsional. Parameter analisis karakteristik cokelat oles menggunakan Uji kuantitatif kadar polifenol total dengan metode Folin Ciocalteau, kadar total flavanoid, asam lemak bebas dan aktivitas antioksidan menggunakan metode $\mathrm{DPPH} I \mathrm{IC}_{50}$, serta analisis organoleptik menggunakan metode hedonik tingkat kesukaan. Fortifikasi cokelat oles menghasilkan kadar asam lemak bebas $0.88 \%$, polifenol 2,6\%, karotenoid $122.12 \mathrm{mg} / \mathrm{g}$ dan aktivitas antioksidan terkuat kisaran 24.1-26.4\%. Cokelat oles variasi cocoa liquor, gula aren dan subtitusi lemak kakao dengan red palm olein, secara umum disukai oleh panelis dari segi rasa dan aroma. pemanfaatan gula aren dan red palm olein memberikan efek fungsional yang baik untuk produk cokelat oles sehingga sangat baik dikonsumsi untuk kesehatan karena bersifat pangan fungsional.
\end{abstract}

Kata kunci: antioksidan, cokelat oles, karotenoid, polifenol, sensori.

\begin{abstract}
West Sulawesi is one of the primary cocoa producers with a contribution of about $22 \%$ of cocoa production in the Sulawesi region. The development of cocoa fermentation and without fermentation in the manufacture of chocolate spread products provide a new alternative as a functional food. This research aims to characterize the activity of antioxidants, polyphenols, carotenoids, and sensory in chocolate products using selected cocoa beans through cocoa liquor variation, palm sugar, and brown olein so obtained the outcome of functional chocolate. A quantitative test of the fortified chocolate spread, as well as the evaluation of antioxidant and sensory parameters in the chocolate spread, were investigated. Polyphenols with Folin Ciocalteau method, flavanoid, free fatty acids, and antioxidant activity were analyzed by the DPPH method of $\mathrm{IC}_{50}$, and while for organoleptic by a hedonic method. Fortification of $0.88 \%$ free fatty acids, polyphenols $2.6 \%, 122.12 \mathrm{mg} / \mathrm{g}$ carotenoids, $24.1-26.4 \%$ antioxidant activity per $100 \mathrm{~g}$ chocolate spread was conducted. Chocolate spread variations of cocoa liquor, palm sugar, and fat replacer with red palm olein, generally liked by panelists in terms of taste and
\end{abstract}


flavor. The utilization of palm sugar and red olein provides an excellent functional effect for chocolate products, so it is well consumed for health because it is a functional food.

Keywords: antioxidant, chocolate spread, carotenoid, polyphenols, sensory.

\section{PENDAHULUAN}

Cokelat merupakan makanan yang memiliki rasa yang unik dan menarik serta bermanfaat untuk kesehatan (Serafini et al., 2003). Cokelat adalah produk makanan yang dicintai oleh banyak orang karena karakteristik kualitas yang diinginkan seperti mengkilap (gloss) di permukaan, snap ketika patah, tekstur halus dan meleleh di mulut (mouthfeel). Kualitas ini terkait erat dengan komponen lemak kakao yang ada dalam cokelat, yang keras dan meleleh pada suhu kamar karena adanya komponen senyawa 2-oleodisaturated trigylcerides dengan jumlah $80 \%$ (Beckett, 2009; Jeyarani et al., 2013). Biji kakao kaya akan antioksidan, termasuk katekin, epicatechin dan procyanidins, polifenol yang mirip dengan yang ditemukan pada anggur dan teh (Carnésecchi et al., 2002; Grassi et al., 2005). Pada umumnya biji kakao fermentasi diperuntukkan untuk keperluan makanan karena kebanyakan produsen olahan kakao mengedepankan aspek cita rasa pada produknya. Proses fermentasi dapat meningkatkan kualitas dan mengembangkan citarasa, aroma, dan mengurangi rasa pahit serta sepat pada biji kakao selain itu pada proses fermentasi terjadi pembentukan senyawa prekusor aroma (Misnawi et al., 2003). Aspek fitokimia, biji kakao tanpa fermentasi berpotensi sebagai neutrisetikal sehingga biji kakao tanpa fermentasi ditujukan untuk kebutuhan health food karena mengandung banyak polifenol.

Red palm olein (RPOL) merupakan salah satu jenis minyak sawit yang mengandung zat warna karotenoid dan $\beta$ karoten alami yang cukup tinggi dibandingkan dengan minyak goreng lain. $\beta$-karoten merupakan antioksidan alami yang berperan penting dalam mempertahankan mutu produk pangan.Jika diperlukan, olein sawit ini bisa dicampur dengan berbagai minyak makan lainnya, sehingga olein sawit sering disebut dengan blending partner (Al-Saqer et al., 2004; El-Hadad et al., 2011). Oleh karena itu minyak Red palm olein (RPOL) dapat dijadikan alternatif pengganti sebagian lemak cokelat dalam formulasi cokelat oles.

Penelitian Manzocco et al. (2014) karakteristik fisik cokelat oles menggunakan minyak bunga matahari dan minyak bunga zaitun yang dikombinasi dengan minyak sawit untuk menghasilkan produk yang rendah lemak. Pembuatan cokelat oles dengan mengganti lemak kakao menggunakan red palm olein (RPOL) pada tingkaan level 20, 40, 60, 80 dan $100 \%$, sehingga diperoleh batas fortifikasi berkisar 20\% (El-Hadad et al., 2011). Penelitian Jeyarani et al. (2013) fortifikasi minyak kedelai dan minyak sawit dalam pembuatan cokelat oles untuk meningkatkan kandungan omega-3. Kombinasi minyak biji kapas dan RPOL sebagai pengganti lemak kakao untuk meningkatkan kandungan antioksidan dalam produk cokelat oles (El-kalyoubi et al., 2011). Penelitian lain Amevor et al. (2018) fortifikasi minyak kacang mete untuk meningkakan karakterisik fisik dan sensori cokelat oles. Salah satu hasil olahan biji kakao yang memiliki prospek untuk dikembangkan adalah cokelat oles. Penelitian tentang fortifikasi cokelat oles sudah pernah dilakukan oleh peneliti lain, namun penelitian tentang penggunaan biji kakao pilihan yang berasal dari klon 
Sulawesi Barat menjadi produk cokelat oles belum pernah dilakukan. Substitusi lemak kakao dengan minyak palm olein kaya karoten diharapkan dapat meningkatkan karakteristik fungsional yang meliputi fisik, kimia, sensori dan antioksidan. Oleh karena itu, dilakukan proses pengembangan dan evaluasi sifat fisikokimia coklat oles fungsional.

\section{TUJUAN PENELITIAN}

Penelitian ini bertujuan untuk mengembangkan biji kakao klon Sulawesi Barat menjadi produk cokelat oles dengan karakteristik fisikokimia dan sensori yang baik, serta memiliki kandungan antioksidan yang bermanfaat untuk konsumen.

\section{METODE PENELITIAN}

\section{Waktu dan Tempat Penelitian}

Penelitian ini dilaksanakan di Teaching Industri dan Laboratorium Biokimia Fakultas Matematika dan IImu Pengetahuan Alam Universitas Hasanuddin Makassar.

\section{Alat dan Bahan}

Peralatan yang digunakan meliputi water bath (Memmert WNB 7 Basic control) Hettich Zentrifugen EBA-20, rotary evaporator (Buchi), Hitachi centrifuge brands, spektrofotometer UV/Vis Shimadzu, roasting machine (KL Protech Type Number 043.13 P033 capacity $15 \mathrm{~kg}$ ), nibs separator machine (KL Protech Type Number 049.13P043), stone mill (KL Protech Type Number 066.13P063) dan ball mill (ball mill mini KL Protech Type Number 041.,13P028).

Biji kakao fermentasi dan non fermentasi klon Sulawesi Barat diperoleh dari petani di Propinsi Sulawesi Barat, red palm olein (RPOL) dari Salmira Nutri Palma Nabati, lecithin dari Sigma-Aldrich (St. Louis, Missouri, United States), cocoa butter dari Mars Symbioscience Company (Makassar, South Sulawesi, Indonesia), skim milk (NZMP New Zealand), dan gula aren. Bahan kimia kualitas pro analysis (PA) yakni hexane (CAS: 110-54-3), Sodium carbonate (CAS: 497-19-8) dan BHT (Butylated Hydroxytoluene ) dari Merck Millipore (Burlington, Massachusetts, United States), DPPH (D4313, CAS: 1898-66-4) dari Tokyo Chemical Industry (Tokyo, Japan), Folin Ciocalteaue (109001), while aluminium chloride (254134, CAS: 12125-02-9), sodium nitrate (CAS: 7631-99-4), Gallic acid (CAS: 149-91-7) dan sodium hydroxide (CAS: 1310-73-2) dari SigmaAldrich (St. Louis, Missouri, United States).
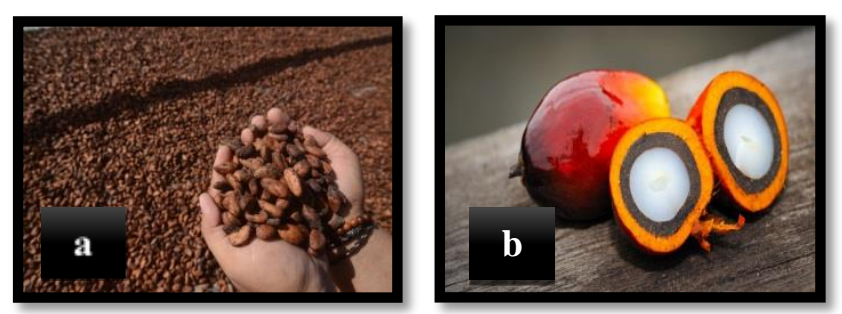

Gambar 1. Bahan olahan cokelat oles: a) biji kakao klon sulawesi barat, dan b) red palm olein

\section{Rancangan Penelitian}

Rancangan penelitian menggunakan Rancangan Acak Kelompok (RAK) dengan tiga kali ulangan, menggunakan software SPSS versi 16 , dapat dilihat pada tabel 1 . 
Tabel 1. Variasi pembuatan cokelat oles

\begin{tabular}{c|c|c|c|c|c|c|c}
\hline $\begin{array}{c}\text { Sam } \\
\text { pel }\end{array}$ & $\begin{array}{c}\text { Coc } \\
\text { oa } \\
\text { liqu } \\
\text { or } \\
(\%)\end{array}$ & $\begin{array}{c}\text { Gu } \\
\text { la } \\
\text { ar } \\
\text { en } \\
(\% \\
\text { ) }\end{array}$ & $\begin{array}{c}\text { Re } \\
\text { pal } \\
\mathbf{m} \\
\text { ole } \\
\text { in } \\
(\%\end{array}$ & $\begin{array}{c}\text { Su } \\
\text { su } \\
\text { Ski } \\
\mathbf{m} \\
(\%)\end{array}$ & $\begin{array}{c}\text { Lesi } \\
\text { tin } \\
(\%)\end{array}$ & $\begin{array}{c}\text { Vani } \\
\text { la } \\
(\%)\end{array}$ & $\begin{array}{c}\text { Gar } \\
\text { am } \\
(\%)\end{array}$ \\
\hline $\begin{array}{c}\text { A1B } \\
1\end{array}$ & 12 & 45 & 20 & 20 & 2 & 0.5 & 0.5 \\
\hline $\begin{array}{c}\text { A2B } \\
1\end{array}$ & 12 & 40 & 20 & 20 & 2 & 0.5 & 0.5 \\
\hline $\begin{array}{c}\text { A3B } \\
1\end{array}$ & 12 & 35 & 20 & 20 & 2 & 0.5 & 0.5 \\
\hline $\begin{array}{c}\text { A1B } \\
2\end{array}$ & 17 & 45 & 20 & 20 & 2 & 0.5 & 0.5 \\
\hline $\begin{array}{c}\text { A2B } \\
2\end{array}$ & 17 & 40 & 20 & 20 & 2 & 0.5 & 0.5 \\
\hline $\begin{array}{c}\text { A3B } \\
2\end{array}$ & 17 & 35 & 20 & 20 & 2 & 0.5 & 0.5 \\
\hline $\begin{array}{c}\text { A1B } \\
3\end{array}$ & 22 & 45 & 20 & 20 & 2 & 0.5 & 0.5 \\
\hline $\begin{array}{c}\text { A2B } \\
3\end{array}$ & 22 & 40 & 20 & 20 & 2 & 0.5 & 0.5 \\
\hline $\begin{array}{c}\text { A3B } \\
3\end{array}$ & 22 & 35 & 20 & 20 & 2 & 0.5 & 0.5 \\
\hline
\end{tabular}

\section{Analisis Sampel}

Uji kuantitatif kadar polifenol total dengan metode Folin Ciocalteau (Godočiková et al., 2017), uji kadar total flavanoid (Shanmugapriya et al., 2011), pengujian asam lemak bebas (El-Hadad et al., 2011), analisis kandungan antioksidan menggunakan metode DPPH IC $\mathrm{I}_{50}$ (Galvan D'Alessandro et al., 2012) dan analisis organoleptik menggunakan metode hedonik tingkat kesukaan dengan parameter rasa, aroma, tekstur dan warna pada skala penilaian ( 1 = sangat tidak suka; $2=$ tidak suka; $3=$ agak suka; $4=$ suka; dan $5=$ sangat suka) dan jumlah panelis sebanyak 31 orang dengan rentang usia 18-21 tahun (wanita $75 \%$ dan pria $25 \%$ ) (Stokes et al., 2017).

\section{Preparasi Sampel}

Buah kakao dibelah dan disortasi untukmemisahkan biji yang berkualitas baik dan buruk. Biji kakao tanpa fermentasi dipisahkan dan dikeringkan, sedangkan biji kakao fermentasi terlebih dahulu disimpan selama 4-5 hari dan setiap hari dilakukan proses pengadukan agar proses fermentasi merata, setelah proses fermentasi selesai, maka dilakukan proses pengeringan dibawah sinar matahari sampai kadar air maksimal 7.5\%. Biji kakao fermentasi disangrai menggunakan mesin penyangrai (roasting) pada suhu 100$105^{\circ} \mathrm{C}$ selama 40 menit. Biji kakao tanpa fermentasi tidak dilakukan penyangraian.

\section{Pembuatan Produk Cokelat Oles}

Proses pembuatan cokelat oles dilakukan dengan menimbang nibs kakao fermentasi sebanyak $900 \mathrm{~g}$ dan nibs kakao tanpa fermentasi $600 \mathrm{~g}$ sehingga perbandingan $60: 40 \%$. Kemudian digiling pada mesin stone mill menjadi pasta kakao atau cocoa liquor, kemudian di formulasikan sesuai tabel 1 . Selanjutnya diolah dimesin ball mill selama 12 jam pada suhu $50^{\circ} \mathrm{C}$ pada kecepatan $50 \mathrm{rpm}$, sehingga diperoleh cokelat oles.

\section{Analisa Data}

Hasil pengujian akan dianalisis menggunakan software SPSS versi 16 untuk analisis keragaman (ANOVA), dilanjutkan uji tukey jika terdapat perlakuan yang berpengaruh nyata.

\section{HASIL DAN PEMBAHASAN}

\section{Kadar Asam Lemak Bebas Selai Cokelat}

Asam lemak bebas (ALB) merupakan salah satu indikator kerusakan mutu produk pangan karena dapat mempengaruhi nilai gizi dari bahan pangan, sehingga menjadikan bahan pangan kurang menarik serta cita rasa yang tidak enak. Hasil analisis sidik ragam terhadap kadar asam lemak bebas diperoleh nilai signifikan 0.072 $(>0.05)$, hal ini menandakan bahwa formulasi yang diterapkan tidak berpengaruh nyata kadar asam lemak bebas cokelat oles yang dihasilkan. Nilai rata-rata kandungan asam lemak bebas selai cokleat berdasarkan formulasi yang diterapkan pada gambar 2 . 


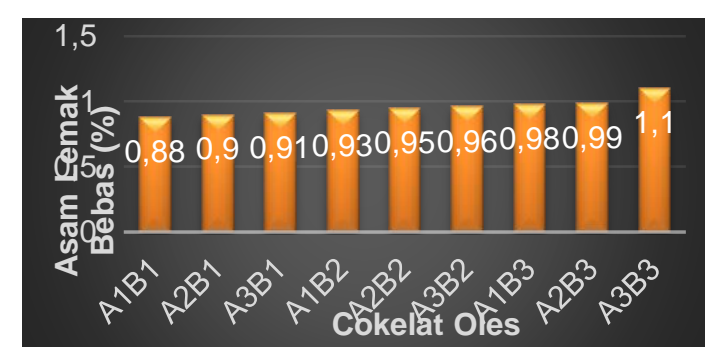

Gambar 2. Kadar asam lemak bebas selai cokelat

Kadar asam lemak bebas cokelat oles yang dihasilkan pada penelitian ini sangat rendah, berkisar antara rentang 0.88-1.1\%. hal ini disebabkan lemak kakao yang merupakan bahan utam dalam pembuatan cokelat, disubtitusi dengan red palm olein dengan tingkatan level $20 \%$, sehingga dapat menurunkan kadar asam lemak bebas dari cokelat oles. Penelitian Elkalyoubi et al. (2011) menggunakan fat replacer atau pengganti lemak kakao dengan menggunakan kombinasi minyak kapas dan red palm olein pada variasi 25 , 50, 75 dan 100\% sehingga diperoleh cokelat oles yang rendah lemak. Menurut El-Hadad et al. (2011) penggunaan red palm olein untuk menggantikan lemak kakao, maksimal 20\% untuk memperoleh cokelat oles dengan karakteristik fisik, kimia dan sensori yang dapat diterima oleh konsumen.

\section{Kadar Total Polifenol}

Polifenol dalam bentuk asam polifenol (hydroxybenzoic dan hydroxycinnamic acids), polifenol (hydrolyzable dan tannin), serta flavonoid merupakan komponen yang berfungsi melindungi tanaman, buahbuahan dan sayuran dari kerusakan oksidatif dan kandungan antioksidan yang dapat melindungi manusia. Bermanfaat melindungi tubuh dari radikal bebas, mengurangi stress, penyakit jantung, tekanan darah tinggi, antikanker, menurunkan kolesterol dan resiko serangan jantung (Do et al., 2014). Berdasarkan analisis sidik ragam terhadap kadar total polifenol diperoleh nilai signifikan $\quad 0.000 \quad(p<0.05)$,hal ini menunjukkan bahwa formulasi yang diterapkan berpengaruh nyata terhadap kandungan total polifenol pada cokelat oles. Hasil uji lanjut menggunakan metode tukey menunjukkan bahwa beberapa perlakuan formulasi berbeda nyata pada kadar total polifenol dimana terdapat kecenderungan semakin tinggi konsentrasi cocoa liquor maka kandungan polifenol pada cokelat oles akan semakin meningkat. Sebaliknya penurunan konsentrasi gula merah dalam formulasi selai coklat cenderung menurunkan kadar total polifenol pada cokelat oles.

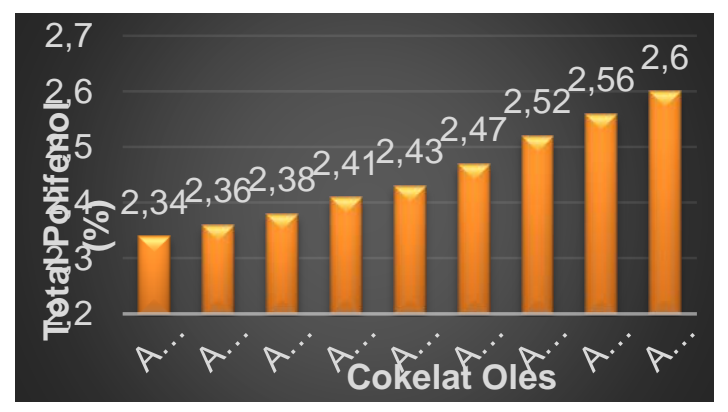

Gambar 3. Kadar total polifenol cokelat oles

Hasil analisis total polifenol pada gambar 3 , menunjukkan sampel A3B3 memiliki kadar total polifenol tertinggi sebesar $2.6 \%$, sedangkan kadar total polifenol terendah sampel A1B1 sebesar 2.34\%. kadar keseluruhan cokelat oles berkisar 2.34 $2.6 \%$, variasi penambahan cocoa liquor dan red palm olein yang berbeda memberikan hasil yang berbeda pula namun perbedaannya tidak terlau signifikan. Penelitian Afoakwa et al. (2009) dan El-Hadad et al. (2011) buah kakao dan red palm olein (RPOL) kaya akan antioksidan alami seperti katekin, epikatekin, prosianidin dan polifenol, 
senyawa tersebut sama dengan yang ditemukan pada bahan pangan seperti teh dan wine.

\section{Total Karotenoid}

Minyak kelapa sawit adalah salah satu dari 17 minyak dan lemak yang dihasilkan dan diperdagangkan di seluruh dunia. Minyak kelapa sawit mentah yang diekstrak pada kondisi suhu tropis dan memiliki warna merah oranye, karena kandungan karoten yang tinggi. Oleh karena itu, dianggap sebagai alam yang kaya sumber karoten (500 - $1500 \mathrm{ppm}$ ), serta tocols (700 -1000 ppm) (El-Hadad et al., 2011; Mayamol et al., 2007). Produk hasil kombinasi dengan red palm olein memiliki warna merah emas yang terang karena mengandung karoten dan tocols (Al-Saqer et al., 2004). Berdasarkan analisis sidik ragam terhadap kadar total karotenoid diperoleh nilai signifikan 0.497 ( $p>0.05$ ), hal ini menunjukkan bahwa formulasi yang diterapkan berpengaruh yang signifikan terhadap kadar karotenoid pada cokelat oles. Hasil uji tukey menunjukkan bahwa beberapa perlakuan formulasi berbeda nyata pada kadar total karotenoid, dimana penambahan red palm olein memberikan dampak pada peningkatan kadar karotenoid pada produk cokelat oles.

Hasil analisis pada gambar 4, menunjukkan bahwa kadar karotenoid produk cokelat oles berkisar antara 121.84$122.12 \mathrm{mg} / \mathrm{g}$. Penambahan red palm olein sekitar 20\% untuk menggantikan lemak kakao memberikan peningkatan terhadap kadar karotenoid cokelat oles. Menurut ElHadad et al. (2011) penggunaan red palm olein untuk menggantikan lemak kakao maksimal $20 \%$ dari komposisi produk, hal ini akan meningkatkan kadar karotenoid dan antioksidan dalam produk cokelat oles.

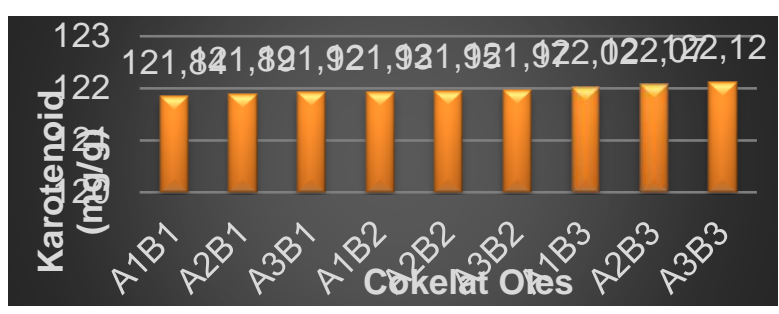

Gambar 4. Kadar total karotenoid cokelat oles

\section{Aktifitas Antioksidan (DPPH IC 50 )}

Analisis $\mathrm{IC}_{50}$ berbanding terbalik dengan antioksidan, karena mengekspresikan jumlah antioksidan yang diperlukan untuk mengurangi konsentrasi DPPH sebesar 50\%, yang diperoleh dengan interpolasi dari analisis regresi linier (Liu et al., 2009). Nilai IC $_{50}$ yang rendah menunjukkan aktivitas antioksidan yang lebih tinggi dari suatu senyawa, begitupula sebaliknya. Gambar 5 menunjukkan nilai $\mathrm{IC}_{50}$ dalam perhitungan kadar radikal bebas DPPH dari cokelat oles. Ditemukan bahwa sampel A1B1, A2B1 dan A3B1 memiliki aktivitas radikal bebas DPPH terkuat dengan kisaran 24.1-26.4, semakin rendah nilai $\mathrm{IC}_{50}$ maka akan semakin kuat aktivitas antioksidan dari bahan tersebut. Dari hasil analisis aktivitas antioksidan untuk semua sampel ttergolong dalam kategori aktivitas antioksidan yang baik karena rata-rata dibawah kisaran $50 \%$. Menurut penelitian Sundram (2005) tingginya kadar polifenol dan karotenoid dan rendahnya kadar asam lemak bebas serta tingginya aktivitas antioksidan dalam cokelat oles akan dapat berfungsi sebagai pangan fungsional dan dapat dikonsumsi oleh anak-anak dan dewasa, karena bermanfaat sebagai anti-kanker, meningkatkan immunitas dan menangkal radikal bebas. 


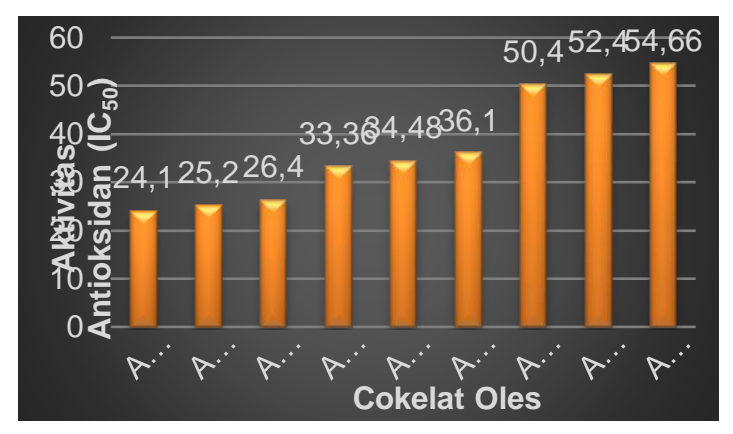

Gambar 5. Aktivitas antioksidan $\left(\mathrm{IC}_{50}\right)$ coklat oles

\section{Uji Hedonik}

Evaluasi sensorik terhadap produk cokelat oles dilakukan dengan uji hedonic tingkat kesukaan berdasarkan penilaian oleh 33 panelis. Parameter penilaian meliputi warna, aroma, rasa dan tekstur. Berdasarkan hasil sidik ragam pada attribut organoleptik yaitu warna, aroma, rasa dan tekstur untuk sembilan sampel cokelat oles pada tabel 2, parameter warna dan tesktur menunjukkan nilai yang tidak signifikan ( $p>0.05$ ) yang berarti perlakuan penambahan cocoa liquor, red palm olein dan gula merah tidak memberikan perbedaan yang nyata terhadap warna dan tekstur pada seluruh sampel produk cokelat oles yang dinilai oleh panelis. Parameter aroma dan rasa menunjukkan hasil yang signifikan $(p<0.05)$, berarti perlakuan penambahan cocoa liquor, red palm olein dan gula merah memberikan perbedaan yang nyata terhadap aroma dan rasa pada seluruh sampel produk cokelat oles yang dinilai oleh panelis.

Tabel 2. Analisis ANOVA produk cokelat oles

\begin{tabular}{l|c|c|c|c|}
\hline Parameter & \multirow{2}{*}{ df } & \multirow{2}{*}{ Mean } & $\mathbf{F}_{\text {nitung }}$ & $\mathbf{F}_{\text {tabel }}$ \\
\cline { 4 - 5 } & & & \multicolumn{2}{|c}{$5 \%$} \\
\hline Warna & 8 & 0.54 & 1.56 & 0.140 \\
\hline Aroma & 8 & 4.14 & 12.29 & 0.000 \\
\hline Rasa & 8 & 0.86 & 3.07 & 0.003 \\
\hline Tekstur & 8 & 0.06 & 0.29 & 0.969 \\
\hline
\end{tabular}

Perbedaan tingkat kesukaan terhadap parameter rasa dan aroma dari cokelat oles disebabkan penggunaan pemanis gula aren. Pemanis gula merah merupakan pemanis alami dengan nilai kalori yang rendah. Penggunaan gula aren dalam bentuk blended sebagai pemanis pada produk cokelat oles baru pertama kali dilaporkan dalam penelitian, sehingga dapat menjadi pemanis yang baik digunakan untuk bahan pangan.

\section{KESIMPULAN}

Cokelat oles variasi cocoa liquor, gula aren dan subtitusi lemak kakao dengan red palm olein, secara umum disukai oleh panelis dari segi rasa dan aroma. penggunaan nibs kakao yang dikombinasi dari kakao fermentasi dan non fermentasi, penggunaan pemanis alami gula aren dan subtitusi lemak kakao dengan red palm olein memberikan perubahan yang signifkan dari segi sensoris produk, namun memberikan pengaruh fungsional terhadap cokelat oles, karena dapat meningkatkan kadar polifenol, karotenoid, dan antioksidan serta menurunkan kadar asam lemaka bebas dalam produk cokelat oles. Fortifikasi cokelat oles dapat menjadi alternatif pangan fungsional yang dapat dinikmati oleh semua kalangan baik anakanak, remaja dan dewasa.

\section{DAFTAR PUSTAKA}

Afoakwa, E. O., Paterson, A., Fowler, M., \& Ryan, A. (2009). Matrix effects on flavour volatiles release in dark chocolates varying in particle size distribution and fat content using GCmass spectrometry and GColfactometry. Food Chemistry, 13, 208-215.

https://doi.org/10.1016/j.foodchem.20 08.07.088

Al-Saqer, J. M., Sidhu, J. S., Al-Hooti, S. N., Al-Amiri, H. A., Al-Othman, A., Al-Haji, L., Ahmed, N., Mansour, I. B., \& Minal, 
J. (2004). Developing functional foods using red palm olein. IV. Tocopherols and tocotrienols. Food Chemistry, 85(4), 579-583. https://doi.org/10.1016/j.foodchem.20 03.08 .003

Amevor, P. M., Laryea, D., \& Barimah, J. (2018). Sensory evaluation, nutrient composition and microbial load of cashew nut-chocolate spread. Cogent Food \& Agriculture, 4(1), 1-10. https://doi.org/10.1080/23311932.201 8.1480180

Beckett, S. T. (2009). Traditional Chocolate Making. In Industrial Chocolate Manufacture and Use: Fourth Edition. https://doi.org/10.1002/97814443015 88.ch1

Carnésecchi, S., Schneider, Y., Lazarus, S. A., Coehlo, D., Gossé, F., \& Raul, F. (2002). Flavanols and procyanidins of cocoa and chocolate inhibit growth and polyamine biosynthesis of human colonic cancer cells. Cancer Letters, 175(2),

147-155.

https://doi.org/10.1016/S0304-

3835(01)00731-5

Do, Q. D., Angkawijaya, A. E., TranNguyen, P. L., Huynh, L. H., Soetaredjo, F. E., Ismadji, S., \& Ju, Y. H. (2014). Effect of extraction solvent on total phenol content, total flavonoid content, and antioxidant activity of Limnophila aromatica. Journal of Food and Drug Analysis, 22, 296-302. https://doi.org/10.1016/j.jfda.2013.11. 001

El-Hadad, N. N. M., Youssef, M. M., Abd ElAal, M. H., \& Abou-Gharbia, H. H. (2011). Utilisation of red palm olein in formulating functional chocolate spread. Food Chemistry, 124(1), 285290.

https://doi.org/10.1016/j.foodchem.20 10.06.034

El-kalyoubi, M., Khallaf, M. F., Abdelrashid, A., \& Mostafa, E. M. (2011). Quality characteristics of chocolate Containing some fat replacer. Annals of Agricultural Sciences, 56(2), 89-96. https://doi.org/10.1016/j.aoas.2011.05 .009
Galvan D'Alessandro, L., Kriaa, K., Nikov, I., \& Dimitrov, K. (2012). Ultrasound assisted extraction of polyphenols from black chokeberry. Separation and Purification Technology. https://doi.org/10.1016/j.seppur.2012. 03.024

Godočiková, L., Ivanišová, E., \& Kačániová, M. (2017). The Influence of Fortification of Dark Chocolate with Sea Buckthorn and Mulberry on the Content of Biologically Active Substances. Advanced Research in Life Sciences, 1(1), 26-31. https://doi.org/10.1515/arls-20170004

Grassi, D., Lippi, C., Necozione, S., Desideri, G., \& Ferri, C. (2005). Shortterm administration of dark chocolate is followed by a significant increase in insulin sensitivity and a decrease in blood pressure in healthy persons. American Journal of Clinical Nutrition, 81(3), 611-614. https://doi.org/10.1093/ajcn/81.3.611

Jeyarani, T., Banerjee, T., Ravi, R., \& Krishna, A. G. G. (2013). Omega-3 fatty acids enriched chocolate spreads using soybean and coconut oils. Journal of Food Science and Technology, 52, 1082-1088. https://doi.org/10.1007/s13197-0131053-4

Liu, S. C., Lin, J. T., Wang, C. K., Chen, H. Y., \& Yang, D. J. (2009). Antioxidant properties of various solvent extracts from lychee (Litchi chinenesis Sonn.) flowers. Food Chemistry, 114(2), 577581.

https://doi.org/10.1016/j.foodchem.20 08.09.088

Manzocco, L., Calligaris, S., Camerin, M., Pizzale, L., \& Nicoli, M. C. (2014). Prediction of firmness and physical stability of low-fat chocolate spreads. Journal of Food Engineering, 126, 120-125.

https://doi.org/10.1016/j.jfoodeng.201 3.10 .042

Mayamol, P. N., Balachandran, C., Samuel, T., Sundaresan, A., \& Arumughan, C. (2007). Process technology for the 
production of micronutrient rich red palm olein. JAOCS, Journal of the American Oil Chemists' Society, 84, 587-596.

https://doi.org/10.1007/s11746-0071078-9

Misnawi, Jinap, S., Jamilah, B., \& Nazamid, S. (2003). Effects of incubation and polyphenol oxidase enrichment on colour, fermentation index, procyanidins and astringency of unfermented and partly fermented cocoa beans. International Journal of Food Science and Technology, 38(3), 285-295.

https://doi.org/10.1046/j.13652621.2003.00674.x

Serafini, M., Bugianesi, R., Maiani, G., Valtuena, S., De Santis, S., \& Crozier, A. (2003). Plasma antioxidants from chocolate. Nature, 424, 1013-1018. https://doi.org/10.1038/4241013a

Shanmugapriya, K., Saravana, P. S., Payal, H., Peer Mohammed, S., \& Binnie, W. (2011). Antioxidant activity, total phenolic and flavonoid contents of Artocarpus heterophyllus and Manilkara zapota seeds and its reduction potential. International Journal of Pharmacy and Pharmaceutical Sciences, 3(5), 256260.

Stokes, C. N., O'Sullivan, M. G., \& Kerry, J. P. (2017). Hedonic and descriptive sensory evaluation of instant and fresh coffee products. European Food Research and Technology, 243(2), 331-340.

https://doi.org/10.1007/s00217-0162747-4

Sundram, K. (2005). Meeting the Rising Health Awareness: The Palm Oil and Consumer Perception. Palm Oil Developments, 43, 20-28. 